\title{
Biological Control of the Invasive Dryocosmus kuriphilus (Hymenoptera: Cynipidae) - an Overview and the First Trials in Croatia
}

\section{Dinka Matošević ${ }^{1}$, Ambra Quacchia ${ }^{2}$, Éva Kriston ${ }^{3}$, George Melika ${ }^{3}$}

${ }^{1}$ Croatian Forest Research Institute, Cvjetno naselje 41, HR-10450 Jastrebarsko, Croatia

${ }^{2}$ GreenWood Service Srl., Corso Palestro, 7 - 10122 Torino, Italy

3 Plant Health and Molecular Biology Laboratory, National Food Chain Safety Office, Budaörsi út 141-145, H-1118 Budapest, Hungary

$\varangle$ Corresponding author: e-mail: dinkam@sumins.hr

Citation:

MATOŠEVIĆ D, QUACCHIA A, KRISTON É, MELIKA G 2014 Biological Control of the Invasive Dryocosmus kuriphilus (Hymenoptera: Cynipidae) - an Overview and the First Trials in Croatia. South-east Eur for 5 (1): 3-12. DOI: http://dx.doi.org/10.15177/seefor.14-05

Received: 14 May 2014;

Accepted: 1 Jun 2014;

Published online: 16 Jun 2014

\section{Abstract}

Background and Purpose: Dryocosmus kuriphilus is a globally invasive insect pest, spreading very quickly in new habitats and making serious damage to sweet chestnut forests in Croatia and in several other European countries. Indigenous parasitoid species trophically associated with oak gallwasps have adapted to this new host but cannot effectively regulate its population density. Classical biological control using parasitoid Torymus sinensis has been proven to be the only effective method of controlling the populations of $D$. kuriphilus and has been successfully applied in Japan, South Korea, the USA and Italy. The aim of this review paper is to provide overview and up-to date knowledge about biological control of $D$. kurphilus and to describe first steps of introduction of $T$. sinensis to sweet chestnut forests in Croatia.

Conclusions and Future Prospects: Results presented in this paper show adapted biology and behavioural traits of $T$. sinensis to its host $D$. kuriphilus. The history and results of introductions of $T$. sinensis to Japan, the USA, Italy, France and Hungary are shown. The first report of release of $T$. sinensis to sweet chestnut forests in Croatia is given with discussion on native parasitoids attacking $D$. kuriphilus. Possible negative effects of $T$. sinensis on native parasitoid fauna and risks that could influence the successful establishment of $T$. sinensis in Croatia are discussed. Previous experiences have shown that $T$. sinensis can successfully control the population density of $D$. kuriphilus, slowing down the spread and mitigating negative impact of this invasive chestnut pest and keeping the damage of $D$. kuriphilus at acceptable level. High specificity of $T$. sinensis suggests that it has limited potential of exploiting native hosts but further detailed monitoring of native parasitoid and possible interactions with introduced $T$. sinensis is strongly suggested.

Keywords: Torymus sinensis, Dryocosmus kuriphilus, classical biological control, parasitoid, sweet chestnut, host specificity, gallwasp, release 


\section{INTRODUCTION}

Alien species may become invasive in new environment due to - among other factors lack of natural enemies [1, 2]. Such an invasive species can spread quickly and have negative influence on native ecosystems. If it attacks economically important plants, the invasion can develop into a serious problem [3]. Dryocosmus kuriphilus Yasumatsu (Hymenoptera: Cynipide) is globally invasive species and considered as one of the most damaging pests of sweet chestnuts [4]. During its expansion into new territories it has shown all the typical traits of an invasive species: easy establishment, quick spread and damage $[5,6]$. It was first recorded in Croatia in 2010 [7] in Istria and Zagreb area and it spread very quickly to other parts of Croatia [8]. Currently the infestation rates are very high and the pest is spreading to new uninfected areas in Croatia.

Sweet chestnut (Castanea sativa Mill.) plays an important role in Croatian forest ecosystems: this is a multipurpose tree used for timber and tannin production, chestnuts are prized and nutritious food, honey is of high quality and it is a valuable landscape and heritage tree [9]. Sweet chestnut trees and forests in Croatia are threatened by two highly invasive species: chestnut blight (Cryphonectria parasitica (Murrill) Barr. and D. kuriphilus [10, 11]. Chestnut blight fungus has devastated sweet chestnut forests in Croatia and recent research shows that galls of $D$. kuriphilus are facilitating the infection by chestnut blight [12]. These are new negative developments that could worsen the fragile and already weak health status of sweet chestnut forests.

Although within its native range in China D. kuriphilus populations are kept at low densities by natural enemies, in Japan, South Korea, the USA, Italy, Slovenia, Croatia, France and Switzerland the attack rates of indigenous parasitoid species are low (typically less than $2 \%)$ [5, 13-19]. The parasitoid complex which trophically associates with oak gallwasps (Hymenoptera, Cynipidae, Cynipini) in Europe adapted to the native hosts and parasitoids' phenology differs from that of $D$. kuriphilus and thus these species cannot effectively regulate the population density of the new invasive cynipid, D. kuriphilus [20]. Insect communities associated with oak gallwasps, Cynipini, to which $D$. kuriphilus belongs, also include a large number of so-called obligatory cynipid inquilines, Synergini, some of which are lethal to the gall-inducer larvae. No cynipid inquilines were reared from the galls of $D$. kuriphilus yet $[18,21]$.

Classical biological control using parasitoid Torymus sinensis Kamijo (Hymenoptera: Torymidae) has been proven to be the only effective method of controlling the populations of $D$. kuriphilus and has been successfully applied in Japan, South Korea, the USA and Italy [6, 16, 22-25].

The aim of this paper is to provide overview and up-to date knowledge about biological control of $D$. kurphilus so the experiences of the methods used and results achieved in other countries, in as well as outside Europe, can be used in Croatia. First steps of introduction of $T$. sinensis to sweet chestnut forests in Croatia are also presented.

\section{BIOLOGY AND SOME BEHAVIOURAL TRAITS OF TORYMUS SINENSIS}

$T$. sinensis is native to China and is the only parasitoid of $D$. kuriphilus known to be host specific and phenologically well adapted to the biology of its host $[6,16,17,23,26,27]$. The parasitoid has one generation per year, as its host, which is quite different to other native polyphagous parasitoid species that are present in the new invaded areas of $D$. kuriphilus. They mostly have more than one generation per year and their phenology and biology, particularly those from the genus Torymus, are not closely matched with $D$. kuriphilus [28-31]. T. sinensis adults emerge from withered galls, mate and females lay eggs in the newly developed galls of $D$. kuriphilus in spring (mostly late April). Each female can lay 70 eggs on average. The emergence is synchronized with the budburst of 
sweet chestnut and development of new galls [24]. Females locate the host with a combination of visual and olfactory stimuli from fresh galls and chestnut foliage [32] which could also explain its specificity to $D$. kuriphilus. Parasitoid larva feeds ectoparasitically and pupates in late winter the following year. The parasitoid aestivates as larva, and overwinters as last larval or early pupal stage [33]. Females have preovipositon period of 6 days, during which the mating occurs and additional imaginal feeding is necessary for the egg-load development; females lifespan is 37 days in the field [27]. This life longevity makes them suitable for raising and manipulating in the laboratory prior to release in the field. $T$. sinensis selects the body surface of the host larva for oviposition rather than the chamber wall as observed in other Torymus species [27]. According to Piao and Moriya [27] this oviposition behaviour in the selection of the host larva is most probably caused by the adapted ovipositor length of $T$. sinensis to the $D$. kuriphilus gall structure and size compared to other species which makes this parasitoid species more able to exploit the available resources of the host. In Asia and USA $T$. sinensis is able to parasitise larger galls than native parasitoids due to its longer ovipositor $[17,27]$. However, this is different in Europe where a number of native Torymus species (e.g. T. auratus (Müller), T. cyaneus Walker, $T$. flavipes (Walker), T. notatus (Walker)) have the same length of the ovipositor as $T$. sinensis, thus they can parasitize the same sized $D$. kuriphilus galls as $T$. sinensis.

One of the adaptive advantages of $T$. sinensis when compared to other univoltine parasitoids present in the invasion range (e.g. Torymus beneficus Yasumatsu \& Kamijo) of $D$. kuriphilus is only one emergence period without peaks which makes this species better synchronized with its host. This very fine phenological difference together with other morphological features (ovipositor length) makes $T$. sinensis highly efficient as biological agent against $D$. kuriphilus $[34,35]$. In case if mating does not occur, females lay unfertilized eggs, parthenogenetically producing only males
[27]. These details should be considered when planning rearing and release to new sites and proper male/female ratio. Personal experience of authors of this paper (A. Quacchia and G. Melika) has shown ability of $T$. sinensis to survive at $15^{\circ} \mathrm{C}$ when fed with honey up to 4 months. $T$. sinensis also has a specific strategy to survive temporary extinction of its host - a prolonged diapause over 2 years [36] which makes it species specific and less likely to parasitize other members of Cynipidae family (e.g. oak gall wasps, Cynipini).

$T$. sinensis tracks the expanding populations of $D$. kuriphilus [16, 25]. During the early years of the release, population of $T$. sinensis will disperse very slowly and, over the years, the dispersion will be faster and exponential. Two release sites $8 \mathrm{~km}$ away from each other will see the merging of the populations of the parasitoid in 5 years, two sites $20 \mathrm{~km}$ apart in 7 years $[25,37]$.

A study on potential of $T$. sinensis as viable management option for biological control of D. kuriphilus $[4,6]$ has raised some important questions to be further studied and answered: (i) the general risk that $T$. sinensis could shift to native gall wasps related to $D$. kuriphilus and (ii) could hybridize with native Torymus species. It was suggested that a host specificity test should be performed for evidence of attack of native oak galls [6]. First tests were done with $T$. sinensis females offering them alternative host galls: Mikiola fagi Hartig (Diptera: Cecidomyiidae) developing on Fagus, galls of asexual generation of oak gall wasps as Cynips quercusfolii Linnaeus (Hymenoptera: Cynipidae) and Andricus kollari Hartig (Hymenoptera: Cynipidae) and no oviposition was recorded [24]. These tests were considered insufficient $[4,6]$ so additional host range tests have been performed [36]. Seven species of oak cynipids (Cynipidae: Cynipini) which occur at similar times in the field as $D$. kuriphilus were tested: Andricus crispator (Tschek), A. curvator (Hartig), A. cydoniae (Giraud), A. grossulariae (Giraud), A. multiplicatus (Giraud), Biorhiza pallida (Olivier) and Dryocosmus cerriphilus (Giraud). All the seven mentioned oak gallwasp species 
are known to have two alternate generations per year; in spring the sexual generations are developing. These species were chosen for the host specificity tests, proposed by EFSA [4] according to their ecological similarity, spatial and temporal attributes and accessibility and availability for $T$. sinensis at the period of parasitation. Few and brief ovipositor pricking were observed on $A$. cydoniae, B. pallida and $D$. cerriphilus but no eggs were laid [36]. These results additionally confirmed the host specificity of $T$. sinensis. Torymus sinensis was introduced to the USA in late 70s [16], to Japan in 1979 (reviewed in Aebi et al. [5]), to Italy in 2004 [24]. However, no other host than D. kuriphilus was ever mentioned in the literature to be parasitized by introduced $T$. sinensis [38]. The risk assessment of possible shift of $T$. sinensis onto other hosts (native oak gallwasps) was discussed in details in Gibbs et al. [6]. Hybridization of a biological control agent with native species is considered as an environmental risk to non-target species [6]. Till now, the only reported case of $T$. sinensis hybridization is with the native $T$. beneficus in Japan: $T$. sinensis and $T$. beneficus were successfully crossed in the laboratory to produce fertile hybrid females [39]. Hybrids were also detected in the field and their hybrid origin proved with molecular markers [40].

The probability of hybridization with native European Torymus species (Hymenoptera: Toymiidae) was tested in mating experiments on Torymus flavipes (Walker), T. auratus (Muller), T. affinis (Fonscolombe) and T. geranii (Walker). No mate recognition and mating were recorded in the laboratory experiments using these native species [36]. However, these species have potential to hybridize with $T$. sinensis as these closely related species overlap geographically (they may even parasitize identical galls on single chestnut trees), and partially also can overlap in their seasonality. Recently the risk of hybridisation between $T$. sinensis and native Torymus species was evaluated by molecularly analysing Torymus specimens reared from oak and chestnut galls, collected in Switzerland and Italy. Hybridisation between $T$. sinensis and $T$. cyaneus was documented in only one case [38], however, this result must be confirmed.

\section{BIOLOGICAL CONTROL OF D. KURIPHILUS IN JAPAN}

The introduction of $T$. sinensis is regarded as a successful case of classical biological control of invasive species in Japan [23] and was the first introduction of $T$. sinensis as biological control agent outside its native range. $D$. kuriphilus arrived in Japan around 1941 and after long years of research of the host and most suitable control measures, 260 mated females of $T$. sinensis were released in 1982 in Ibaraki prefecture [41]. The parasitoid population grew by factor of 25 times by 1989 [23], the parasitoid expanded its range soon after the release, adults being raised more than $12 \mathrm{~km}$ from release point showing good dispersal ability. In the first few years the parasitoid spread at rate less than $1 \mathrm{~km} /$ year but the speed increased in the following years to app. $60 \mathrm{~km} /$ year. Over the years the parasitoid has dispersed naturally several hundred kilometres from the release point (Figure 2) [23]. The infestation rate of $D$. kuriphilus decreased rapidly to tolerable injury level of 30\% (Figure 1) [23].

This classical biological control program succeeded in drastically reducing the damage caused by $D$. kuriphilus in Japan [42]. Japanese experience shows that the tolerable injury level from $D$. kuriphilus is about $30 \%$ infestation [23]. After the introduction of $T$. sinensis the infestation rates decreased steadily from $43 \%$ to less than $1 \%$ [23] which is the result of established population of introduced $T$. sinensis.

\section{BIOLOGICAL CONTROL OF D. KURIPHILUS IN THE USA}

D. kuriphilus was first observed in the USA in 1974 negatively influencing chestnut production and health status of chestnut trees [16]. T. sinensis was introduced for biological control, expanding together with its host to 


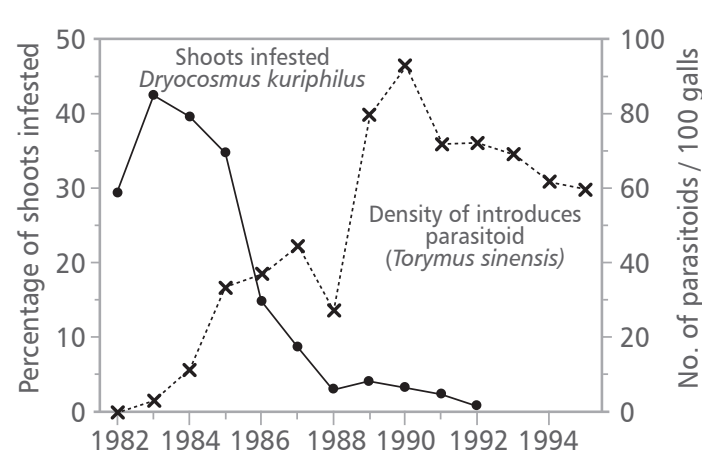

FIGURE 1. Decrease in infestation rate with Dryocosmus kuriphilus after the release of Torymus sinensis in Japan (source Moriya et al. [42])

new sites [16]. Recent study [17] confirmed that $T$. sinensis is the dominant parasitoid of $D$. kuriphilus in eastern USA. T. sinensis was not present in oak galls collected on the sites and it can be considered as specialist on $D$. kuriphilus in North America [17]. Studies [16, 17] have also provided evidence that $T$. sinensis is hyperparasitized by native cynipid parasitoids which could potentially suppress $T$. sinensis populations and influence its potential as biological control agent. At present it is effective control agent of $D$. kuriphilus in the USA [17].

\section{BIOLOGICAL CONTROL OF D. KURIPHILUS IN ITALY}

D. kuriphilus has been introduced to Italy with infested plants around 2002 and quickly spread through Italian peninsula [43]. First releases of $T$. sinensis, raised from galls imported from Japan, were in 2005 (90 females and 80 males) and 2006 (1 058 females and 889 males) [24]. The increase of parasitoid populations has been exponential, surpassing $90 \%$ in 5-7 years after release, which is significantly bigger than the parasitism rate of native parasitoids of 3-5\% [25]. The biological control of D. kuriphilus is giving visible results in Italy, in Cuneo region (the region of first European infestation by $D$. kuriphilus), where first releases began 5-7 years ago. The parasitisation rates nowadays often exceed $85-90 \%$ with a significant reduction

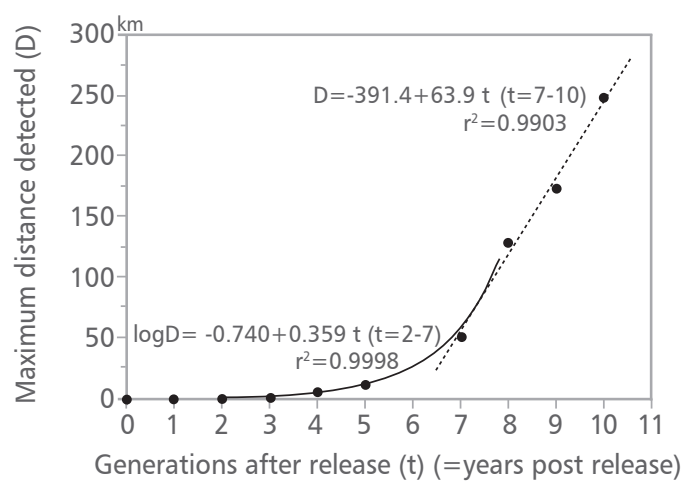

FIGURE 2. Range expansion of Torymus sinensis, relationship between the number of generations (t) after the release in Japan (Tsukuba) in 1982 and maximum distance (D) from the release site to the locality where T. sinensis has been detected (source Moriya et al. [22, 23])

of number of infested leaves and shoots. The galls are decreasing in numbers and vegetative growth of chestnut trees is recovering [25].

\section{BIOLOGICAL CONTROL OF D. KURIPHILUS IN FRANCE}

Based on previous successful operations in other countries, a classical biological control using the parasitoid $T$. sinensis has been implemented in France since 2011 [44]. During the two first years 42 releases of $T$. sinensis were made in different parts of France (one single introduction of 100 a and $50 \hat{0}$ versus two introductions of $50 \propto$ and $25 \hat{\jmath}$ with a one-year interval per site). First results indicate that even though very few specimens of this biocontrol agents were released, the rate of establishment of $T$. sinensis is high (app. 80\%) [44].

\section{BIOLOGICAL CONTROL OF D. KURIPHILUS IN HUNGARY}

In May 2014, T. sinensis was released also in the southwestern part of Hungary, Zala County in two sites (Dobri and Kerkateskánd) where the population of $D$. kuriphilus is rapidly growing [45]. In Dobri were 200 females, while in 
Kerkateskánd 100 females previously mated with males in the laboratory conditions were released. The males and females originate from the Cuneo region in Italy (G. Melika, personal comm.).

\section{NATIVE PARASITOIDS OF D. KURIPHI- LUS IN CROATIA AND POSSIBLE NE- GATIVE EFFECTS OF T. SINENSIS ON NATIVE PARASITOID FAUNA}

After the first record of $D$. kuriphilus in Croatia [7] 15 species of native parasitoids have adapted to the new host in few years [18]. The indigenous parasitoids fauna fails to exert sufficient biological control of $D$. kuriphilus and reduction in leaf area and sweet chestnut fruit yield are reported from all attacked areas in Croatia. Torymus flavipes was the most abundant species and first to adapt to a new host [18], with two more Torymus species ( $T$. geranii and $T$. auratus). The biology of native parasitoids differs from that of $T$. sinensis, where native Torymus species emerge just before the emergence of $D$. kuriphilus (end of May, early June) [46] and have two generations per year [28-31]. Therefore their development is not entirely synchronized with the phenology of D. kuriphilus. Low attack rates of natural parasitoids make therefore $T$. sinensis a viable solution. Visible damage and rapidly expanding pest in Croatian sweet chestnut forests have prompted for initiation of biological control of $D$. kuriphilus. In all invaded sweet chestnut forests in Croatia large and multiple $D$. kuriphilus galls have been found which could also be a reason for low success of native parasitoids but a favourable trait for $T$. sinensis population due to its longer ovipositor and ability to parasitize larger galls [17, 27].

\section{BIOLOGICAL CONTROL OF D. KURIPHILUS IN CROATIA}

The biological control of $D$. kuriphilus in Croatia has started in spring 2014. Before the release all the necessary aspects and precautions have been considered: host-specificity, effects on non-target species, location of the site of first release, good settlement prospects, gall size (larval stage) and national regulations regarding the introduction of alien bio control species. Approximately 1300 withered galls have been imported from Italy in March 2014 from two localities i.e. Borgo d'Ale and Torre Canavese in Torino region, where multiple releases of $T$. sinensis occured and high parasitism rates were achieved. The galls were kept at $7^{\circ} \mathrm{C}$ to delay the emergence of adults and to synchronize it with development of galls in the field. A natural sweet chestnut forest in Pazin (locality Lovrin) (area 12 ha) on Istria Peninsula was chosen as a site of first release of $T$. sinensis. When the $D$. kuriphilus galls started to develop in the field, the withered galls with $T$. sinensis were taken from the fridge and kept at room temperature, until after few days first males and then females started to emerge. They were coupled together (10 females/5 males) in plastic tubes, fed with honey and kept at $15^{\circ} \mathrm{C}$ in climatic chamber $(L: D=12: 12)$ until release. On 11 April 2014, 1200 females and 600 males were released in Pazin (45.233482N; 13.920008E). This is the first attempt of biological control of a forest pest with introduced bio control agent in Croatia and hopefully the population of $T$. sinensis would be dense enough and parasitism rate high so that Pazin site could be used as a "bank" of $T$. sinensis population for raising adults for the release in other parts in Croatia in the next years.

\section{CONCLUSIONS AND FUTURE PROSPECTS}

Release and establishment of $T$. sinensis in Japan, the USA and Italy is an example of successful biological control of an invasive species. However, several risks that could influence the successful establishment of $T$. sinensis should be considered.

Hyperparasitism of $T$. sinensis by native parasitoids could limit the establishment of $T$. sinensis in forest habitats [16, 17]. 
Throughout Europe, Eupelmus urozonus Dalman (Hymenoptera: Eupelmidae) is raised as one of the most common $D$. kuriphilus native parasitoid. This species very often acts as a facultative hyperparasitoid in oak cynipid galls [28]. Thus it is possible that hyperparasitoids can influence the population densities of $T$. sinensis [24], which should be confirmed by further studies.

The sex ratio of first Croatian population of T. sinensis should also be monitored as there is a possibility of male-biased sex ratio due to the failure of mating. This can happen when the density of individuals is low and finding a mate is difficult [24].

The failure in establishment due to the mismatch between the emergence of adults and suitable gall development stage can also pose a risk, but this can easily be avoided by regulating the emergence dates of $T$. sinensis by adjusting the emergence and rearing temperature in laboratory. The unavailability of hosts is not expected to be a risk in the establishment $T$. sinensis population as $D$. kuriphilus is present in high densities in Croatia and expanding its range very quickly. Native parasitoids are not able to influence the population density of $D$. kuriphilus [18] in such an extent that it could cause the extinction of $T$. sinensis population.

All previous experiences have shown that $T$. sinensis can successfully control the population density of $D$. kuriphilus (Figure 1) [17, 23, 24]. The synchrony of biology of $T$. sinensis with the biology of its host and ability to disperse into the invading territory with pest population and spread rapidly (Figure 2) make this parasitoid suitable for mitigating negative impact of this invasive chestnut pest as well as keeping the damage of $D$. kuriphilus at acceptable level. High specificity of $T$. sinensis suggests that it has limited potential of exploiting native hosts [36]. However, there is still a possibility of hybridization with native Torymus species $[6,38]$ so we strongly suggest further detailed monitoring of native parasitoids and possible interactions with introduced $T$. sinensis populations and competition of native and introduced parasitoids in Croatia. To assess indirect effects of introduction of $T$. sinensis (i.e. influence on non-target species) molecular methods will be used for identification of potential hybrids of $T$. sinensis with native Torymus (if any will be found in Croatia).

There is also a possibility of augmentative biological control [6] using native parasitoids in Croatia. Therefore, the research on native parasitoids and their influence on population densities of $D$. kuriphilus will continue, in first as well as in the last invaded sites so the results and effects can be compared with classical biological control using $T$. sinensis. In conclusion, on the basis of the review of references, an extensive experience of scientists and personal experience of the authors, the use of $T$. sinensis as biological control agent together with the potential of natural parasitoids should be considered the best possible solution to control the invasive pest $D$. kuriphilus in natural sweet chestnut forests in Croatia.

\section{Acknowledgement}

D. Matošević would like to thank Giovanni Bosio for help in collecting the galls, Christian Gallo and Krešimir Jakupak for support and help in choosing the site and release in Pazin, Blaženka Ercegovac and Iva Franić for help in laboratory work. The release in Croatia was funded by Croatian Ministry of Agriculture, IPP programme for 2014 with special thanks to Goran Videc for recognizing the importance of biological control. G. Melika is supported by the Hungarian Scientific Research Found (OTKA K101192). 


\section{REFERENCES}

1. LOCKWOOD J, HOOPES M, MARCHETTI M 2006 Invasion Ecology. 1st ed. Blackwell Publishing Ltd, Malden, MA, USA, $304 p$

2. DAVIS M A 2009 Invasion biology. Oxford University Press, Oxford, UK, $244 p$

3. SIMBERLOFF D 2013 Invasive Species: What Everyone Needs to Know. Oxford University Press, Oxford, $352 \mathrm{p}$

4. EFSA 2010 Risk assessment of the oriental chestnut gall wasp, Dryocosmus kuriphilus for the EU territory and identification and evaluation of risk management options. EFSA Journal 8 (6): 1-114. URL: http://www.efsa.europa.eu/en/efsajournal/ doc/1619.pdf (15 March 2014)

5. AEBI A, SCHÖNROGGE K, MELIKA G, ALMA, BOSIO G, QUACCHIA A, PICCIAU L, ABE Y, et al. 2006 Parasitoid recruitment to the globally invasive chestnut gall wasp Dryocosmus kuriphilus. In: Ozaki K, Yukawa J, Ohgushi T, Price P W (eds) Galling Arthropods and Their Associates. Springer Japan KK, Osaka, Japan, pp 103-121. DOI: http:// dx.doi.org/10.1007/4-431-32185-3 9

6. GIBBS M, SCHÖNROGGE K, ALMA A, MELIKA G, QUACCHIA A, STONE G N, AEBI A 2011 Torymus sinensis: a viable management option for the biological control of Dryocosmus kuriphilus in Europe? BioControl 56 (4): 527-538. DOI: http:// dx.doi.org/10.1007/s10526-011-9364-8

7. MATOŠEVIĆ $D$, PERNEK M, HRAŠOVEC B 2010 First record of Oriental chestnut gall wasp (Drycosmus kuriphilus) in Croatia (in Croatian with English summary). Sumar List 134 (9-10): 497-502

8. MATOŠEVIĆ D 2012 Oriental chestnut gall wasp (Dryocosmus kuriphilus) in Croatia (in Croatian with English summary). Radovi (Hrvat šumar inst) 44 (2): 113-123

9. MEDAK J, IDŽOJTIĆ $M$, NOVAK-AGBABA $S$, ĆURKOVIĆ-PERICA M, MUJIĆ I, POLAK I, JURETIĆ D, PRGOMET Ž 2009 Croatia// Following chestnut footprints (Castanea spp), Cultivation and Culture, folklore and history, traditions and uses. In: Bounous G, Beccaro G L (eds) Proceedings of the First European Congress on Chestnut Castanea 2009, Cuneo-Torino, Italy, 13-16 October 2009. International Society for Horticultural Science, Leuven, Belgium, pp 40-43
10. NOVAK-AGBABA S, LIOVIĆ B, PERNEK M 2000 Sweet chesnuts stands (Castanea sativa Mill.) in Croatia and presence of Hypo-virulent strains of the fungus Cryphonectria parasitica (Murr.) Barr. (in Croatian with English su mmary). Radovi (Hrvat šumar inst) 35 (1): $91-110$

11. JEŽIĆ M, KRSTIN L, POLAK I, LIBER Z, IDŽOJTIĆ M, JELIĆ M, MEŠTROVIĆ J, ZEBEC M, ĆURKOVIĆ-PERICA M 2014 Castanea sativa: genotype-dependent recovery from chestnut blight. Tree Genet Genomes 10 (1): 101-110. DOI: http://dx.doi.org/10.1007/ s11295-013-0667-z

12. PROSPERO S, FORSTER B 2011 Chestnut gall wasp (Dryocosmus kuriphilus) infestations: new opportunities for the chestnut blight fungus Cryphonectria parasitica? New Disease Reports 23: 35. DOI: http://dx.doi.org/10.5197 L.2044-0588.2011.023.035

13. OTAKE A 1989 Chestnut gall wasp, Dryocosmus kuriphilus Yasumatsu (Hymenoptera: Cynipidae): analysis of records on cell contents inside galls and emergence of wasps and parasitoids outside galls. Appl Entomol Zool 24 (2): 193-201. DOI: http:/l dx.doi.org/10.1303/aez.24.193

14. MURAKAMI Y, OHKUBO N, MORIYA S, GYOUTOKU Y, KIM C H, KIM J K 1995 Parasitoids of Dryocosmus kuriphilus (Hymenoptera, Cynipidae) in South Korea with particular reference to ecologically different types of Torymus (Syntomaspis) sinensis (Hymenoptera, Torymidae). Appl Entomol Zool 30 (2): 277-284. DOI: http://dx.doi.org/10.1303/ aez.30.277

15. AEBI A, SCHÖNROGGE K, MELIKA G, QUACCHIA A, ALMA A, STONE G N 2007 Native and introduced parasitoids attacking the invasive chestnut gall wasp Dryocosmus kuriphilus. EPPO Bull 37 (1): 166-171. DOI: http://dx.doi.org/10.1111/j.13652338.2007.01099.x

16. COOPER W R, RIESKE L K 2007 Community associates of an exotic gallmaker, Dryocosmus kuriphilus (Hymenoptera: Cynipidae), in eastern North America. Ann Entomol Soc Am 100 (2): 236-244. DOI: http://dx.doi.org/10.1603/00138746(2007)100[236:CAOAEG]2.0.CO;2

17. COOPER W R, RIESKE L K 2011 A native and an introduced parasitoid utilize an exotic gall-maker host. BioControl 56 (5): 725-734. DOI: http://dx.doi. org/10.1007/s10526-011-9350-1 
18. MATOŠEVIĆ D, MELIKA G 2013 Recruitment of native parasitoids to a new invasive host: first results of Dryocosmus kuriphilus parasitoid assemblage in Croatia. Bull Insectology 66 (2): 231-238

19. MELIKA G, MATOŠEVIĆ D, KOS K, BOSIO G, KRISTON E, KRIZBAI L, BOZSÓ M, CSÓKA G, et al. 2013 Native Parasitoids attacking the Chestnut Gallwasp, Dryocosmus kuriphilus (Hymenoptera: Cynipidae), across Italy - Slovenia - Croatia - Hungary. In: Book of Abstracts of II. European Congress of Chestnut, Debrecen, Hungary, 9-12 October 2013.

20. ASKEW $R \quad R$, MELIKA $G$, PUJADE-VILLAR J, SCHÖNROGGE K, STONE G N, NIEVES-ALDREY J L 2013 Catalogue of parasitoids and inquilines in cynipid oak galls in the West Palaearctic. Zootaxa 3643: 1. DOI: http://dx.doi.org/10.11646/ zootaxa.3643.1.1

21. QUACCHIA A, FERRACINI C, NICHOLLS J A, PIAZZA E, SALADINI M A, TOTA F, MELIKA G, ALMA A 2012 Chalcid parasitoid community associated with the invading pest Dryocosmus kuriphilus in north-western Italy. Insect Conserv Diver 6 (2): 114-123. DOI: http://dx.doi.org/10.1111/j.17524598.2012.00192.x

22. MORIYA S, INOUE K, MABUCHI M 1989 The use of Torymus sinensis to control chestnut gall wasp, Dryocosmus kuriphilus. Food Fertil Technol Cent FFTC Tech Bull 118: 1-12

23. MORIYA S, SHIGA M, ADACHI I 2002 Classical biological control of the chestnut gall wasp in Japan. In: Proceedings of the 1st International Symposium on biological control of arthropods, pp 407-415. URL: http://www.invasiveforestinsectandweedbiocontrol. info/international symposium/day5 pdf/moriya.pdf (10 January 2014)

24. QUACCHIA A, MORIYA S, BOSIO G, SCAPIN I, ALMA A 2008 Rearing, release and settlement prospect in Italy of Torymus sinensis, the biological control agent of the chestnut gall wasp Dryocosmus kuriphilus. BioControl 53 (6): 829-839. DOI: http:// dx.doi.org/10.1007/s10526-007-9139-4

25. BOSIO G, ARMANDO M, MORIYA S 2013 Verso il controllo biologico del cinipide del castagno (in Italian). L'Informatore Agrario 14: 60-64

26. KAMIJO K 1982 Two new species of Torymus (Hymenoptera, Torymidae) reared from Dryocosmus kuriphilus (Hymenoptera, Cynipidae) in China and Korea. Kontyû 50: 505-510

27. PIAO C, MORIYA S 1999 Oviposition of Torymus sinensis (Hymenoptera: Torymidae) under natural conditions. Entomol Sci 2: 329-334
28. ASKEW R 1961 On the biology of the Inhabitants of oak Galls of Cynipidae (Hymenoptera) in Britain. Trans Soc Br Entomol 14: 237-268

29. ASKEW R 1961 On the Palearctic species of Syntomaspis Förster (Hym., Chalcidoidea, Torymidae). Entomol Mon Mag 96: 184-191

30. ASKEW R 1965 The biology of the British species of the genus Torymus Dalman (Hymenoptera: Torymidae) associated with galls of Cynipidae (Hymenoptera) on oak, with special reference to alternation of forms. Trans Soc Br Entomol 16: 217232

31. ASKEW R 1966 Observations on the British species of Megastigmus Dalman (Hym., Torymidae) which inhabit Cynipid oak galls. The Entomologist 99: 124-128

32. GRAZIOSI I, RIESKE L K 2013 Response of Torymus sinensis, a parasitoid of the gallforming Dryocosmus kuriphilus, to olfactory and visual cues. Biol Control 67 (2): 137-142. DOI: http://dx.doi.org/10.1016/j. biocontrol.2013.07.012

33. SHIGA M 2009 Life history of an introduced parasitoid, Torymus sinensis, and dynamics of the host-parasitoid system. In: Japan-Italy Joint International Symposium "A Global Serious Pest of Chestnut Trees: Yesterday, Today and Tomorrow", Ibaraki, Japan, 24-25 November 2009, pp 21-22

34. OTAKE A 1987 Comparison of some morphological characters among two strains of Torymus beneficus Yasumatsu et Kamijo and T. sinensis Kamijo (Hymenoptera: Torymidae). Appl Entomol Zool 22 (4): 600-609. DOI: http://dx.doi.org/10.1303/ aez. 22.600

35. SCHÖNROGGE K, MORIYA S, MELIKA G, RANDLE Z, BEGG T, AEBI A, STONE G N 2006 Early parasitoid recruitment in invading cynipid galls. In: Ozaki K, Yukawa J, Ohgushi T, Price P W (eds) Galling Arthropods and Their Associates. Springer Japan KK, Osaka, Japan, pp 91-101. DOI: http://dx.doi. org/10.1007/4-431-32185-3 8

36. QUACCHIA A, ASKEW R, MORIYA S, SCHONROGGE K 2013 Torymus sinensis: Biology, host range and hybridisation. In: Book of Abstracts of II. European Congress of Chestnut, Debrecen, Hungary, 9-12 October 2013.

37. MINISTERO DELLE POLITICHE AGRICOLE, AND ALIMENTARI E FORESTALI, ITALIA 2010 Technical Reference for the Implementation of the Biological Control of Chestnut with Torymus Sinensis (in Italian). 
38. AEBI A, SCHÖNENBERGER N, BIGLER F 2013 Towards an environmental risk assessment of Torymus sinensis against the chestnut gall wasp Dryocosmus kuriphilus in Switzerland. Report for the FOEN, $34 p$

39. MORIYA S, INOUE K, SHIGA M, MABUCHI M 1992 Interspecific relationship between an introduced parasitoid, Torymus sinensis Kamijo, as a biological control agent of the chestnut gall wasp, Dryocosmus kuriphilus Yasumatsu, and an endemic parasitoid, T. beneficus Yasumatsu \& Kamijo. Acta Phytopathol Entomol Hung 27: 479-483

40. YARA $K$, YANO E, SASAWAKI T, SHIGA M 2000 Detection of hybrids between introduced Torymus sinensis and native $T$. beneficus (Hymenoptera: Torymidae) in central Japan, using malic enzyme. Appl Entomol Zool 35 (2): 201-206. DOI: http:// dx.doi.org/10.1303/aez.2000.201

41. OTAKE A, SHIGA M, MORIYA S 1982 A study on parasitism of the chestnut gall wasp, Dryocosmus kuriphilus Yasumatsu (Hymenoptera: Cynipidae) by parasitoids indigenous to Japan. Bull Fruit Tree Res Stn A9: 177-192
42. MORIYA S, INOUE K, OTAKE A, SHIGA M, MABUCHI M 1989 Decline of the chestnut gall wasp population, Dryocosmus kuriphilus Yasumatsu (Hymenoptera: Cynipidae) after the establishment of Torymus sinensis Kamijo (Hymenoptera: Torymidae). Appl Entomol Zool 231-233. DOI: http://dx.doi.org/10.1303/aez.24.231

43. BRUSSINO G, BOSIO G, BAUDINO M, GIORDANO R, RAMELLO F, MELIKA G 2002 Pericoloso insetto esotico per il castagno europeo (in Italian). L'Informatore Agrario 58: 59-62

44. BOROWIEC N, THAON M, BRANCACCIO L, WAROT S, VERCKEN E, FAUVERGE X, RIS N, MALAUSA J C 2013 Classical biological control program against the chestnut gallwasp Dryocosmus kuriphilus in France. In: Book of Abstracts of II. European Congress of Chestnut, Debrecen, Hungary, 9-12 October 2013.

45. SZABO G, KRISTON E, BUJDOSO B, BOZSÓ M, KRIZBAI L, MELIKA G 2014 The sweetchestnut gallwasp (Dryocosmus kuriphilus Yasumatsu 1951) (Hymenoptera: Cynipidae): current distribution in Hungary and its natural enemies (in Hungarian). Növényvédelem 50 (2): 49-56

46. SANTI F, MAINI S 2011 New association between Dryocosmus kuriphilus and Torymus flavipes in chestnut trees in the Bologna area (Italy): first results. Bull Insectology 64 (2): 275-278 